\title{
Micro-controller Based Mobile Weather Monitor System
}

\author{
Abubakar Ibrahim Musa ${ }^{1, \text { *, Sulaiman Muhammad Bashir }}{ }^{2}$ \\ ${ }^{1}$ National Centre for Petroleum Research and Development (Energy Commission of Nigeria), Abubakar Tafawa Balewa University Bauchi, \\ Nigeria \\ ${ }^{2}$ Department of Electrical and Electronics Engineering, Abubakatar Tafawa Balewa University, Bauchi, Nigeria
}

Email address:

sadikmusa09@yahoo.con (A. I. Musa), sulaimanbashir22@gmail.com (S. M. Bashir)

${ }^{*}$ Corresponding author

\section{To cite this article:}

Abubakar Ibrahim Musa, Sulaiman Muhammad Bashir. Micro-controller Based Mobile Weather Monitor System. American Journal of Embedded Systems and Applications. Vol. 6, No. 1, 2018, pp. 23-29. doi: 10.11648/j.ajesa.20180601.14

Received: May 1, 2018; Accepted: June 4, 2018; Published: June 15, 2018

\begin{abstract}
Stored data and records of weather parameter like temperature, atmospheric pressure, relative humidity, wind speed measured remotely by using appropriate sensors is important in environmental, weather monitoring and many industrial processes. A device for weather monitoring through measuring, processing and recording is developed to monitor and display the atmospheric temperature, atmospheric pressure, relative humidity, solar radiation and wind speed. The aim is to design and implement mobile weather monitoring system that can be remotely used. The materials that were used including: Anemometer (wind speed sensor), DHT11 (temperature and relative humidity sensor), MPX5100AP (pressure sensor), LDR (Light Dependent Resistor) for light intensity 16x2 LCD (Liquid Cristal Display), a microcontroller, and a Memory Card (MMC). At the end, a weather monitoring system was implemented and it was used to monitor five weather parameters and store in the memory Card.
\end{abstract}

Keywords: Weather Monitoring. Sensors, Mobile, Microcontroller, Light Intensity, Atmospheric Temperature, Atmospheric Pressure, Relative Humidity, Solar Radiation and Wind Speed Memory Card (MMC)

\section{Introduction}

Weather Monitoring System (WMS) is a device help to keep track of weather parameters. Before now, people have been carrying out the same objectives using different devices, such as satellite, radar until the modern method which is the application of microcontrollers. The device has units as microcontroller, Liquid Crystal Display, power source and parameters from sensors will be processed by microcontroller display on LCD and store in external memory for future purposes. Weather monitoring system is having much usefulness particularly in Communication, Transportation and Agriculture. In Agriculture for example, weather plays a major role in determining the success of agricultural pursuits. Most field crops are dependent solely upon weather to provide life-sustaining water and energy. Livestock are also dependent upon weather for their comfort and food supplies. The connections among weather, climate, and food production have long been recognized and studied. Over the last several decades, it has become increasingly clear that human activities such as fossil- fuel combustion and deforestation are changing the Earth's climate (IPCC 2013). It is likewise clear that these changes have affected and will continue to affect human society, natural ecosystems, and managed ecosystems (IPCC 2013). An extensive body of evidence shows that climate change will continue to have direct and indirect effects on food production throughout the next century [2].

Climate and weather have demonstrable effects on food prices, transportation infrastructure, and the costs and operations of food distributors, affecting food access and stability. Food access is strongly influenced by additional factors outside of the food system, such as household income. The adaptive capacity of food access to changes in climate is potentially very high but varies enormously between high-income and low income countries and individuals, between urban and rural populations, and the ways in which each of these develops in the future [1]. 
The proper knowledge of weather will help us to know the type of crops that can grow in a particular area at a particular time. In this $21^{\text {st }}$ century, weather monitoring holds great importance and have uses in several areas ranging from keeping track of agricultural field weather conditions to industrial conditions monitoring. Weather monitoring would help in keeping track of different climatic behaviours including atmospheric temperature, atmospheric pressure, relative humidity, wind speed, and wind direction, light intensity, rain gauge and many more. The art of weather monitoring and weather forecasting began with early civilizations using reoccurring astronomical and meteorological events to help them monitor seasonal changes in the weather. Around 650 B.C., the Babylonians tried to predict short-term weather changes based on the appearance of clouds and optical phenomena such as haloes. By 300 B.C., Chinese astronomers had developed a calendar that divided the year into 24 festivals, each festival associated with a different type of weather [15].

Around 340 B.C., the Greek philosopher Aristotle wrote a book titled "Meteorological", a philosophical treatise that included theories about the formation of rain, clouds, hail, wind, thunder, lightning, and hurricanes. In addition, topics such as astronomy, geography, and chemistry were also addressed. Aristotle made some remarkably acute observations concerning the weather, along with some significant errors, and his four-volume text was considered by many to be the authority on weather theory for almost 2000 years. Although many of Aristotle's claims were erroneous, it was not until about the 17 th century that many of his ideas were overthrown [16]

Throughout the centuries, attempts have been made to produce forecasts based on weather lore and personal observations. However, by the end of the Renaissance, it had become increasingly evident that the speculations of the natural philosophers were inadequate and that greater knowledge was necessary to further our understanding of the atmosphere. In order to do this, instruments were needed to measure the properties of the atmosphere, such as moisture, temperature, and pressure. The first known design in western civilization is hygrometer, an instrument to measure the humidity of air, was described by Nicholas Cusa (German) in the mid-fifteenth century. Galileo Galilei (Italian) invented an early thermometer in 1592 or shortly thereafter; and Evangelista Torricelli (Italian) invented the barometer for measuring atmospheric pressure in 1643 [17]

\section{Literature Review}

A lot of research works were conducted in the areas of weather monitoring over the past decades. Some of the research works are hereby reviewed, taking into consideration their major components used, their sizes and their costs. Various researchers used different transceivers in transmitting parameters from transmitting unit to receiving unit. Among them are those that used RF module, Bluetooth, Short Message Service (SMS) and ZigBee
Technology.

Edgar et al. worked on portable weather system for measuring and monitoring temperature, relative humidity and pressure based on Bluetooth communication. The system was divided into subsystems; main control, weather measure control and Bluetooth control. Main control is responsible for initializing and prioritizing of processor tasks. Weather control is responsible for calibrating and controlling the sensor in the system. It also computes the relative humidity, average temperature, pressure and altitude. Bluetooth control is responsible for calibrating and handling Bluetooth communication. It looks for Bluetooth devices in its vicinity to establish communication and data transfer [3].

Nhivekar and Mudholker developed data logger and remote monitoring system for multiple parameter measurement applications. They used ATMEGA32 microcontrollers with two physical parameter sensors (LM 35 and module SY - HS 220, temperature and relative humidity sensor respectively). LCD 16 by 2 to display the received data by the microcontroller, multi media memory card (MMC) give non volatile storage for the system, then TTL to RS 232 converter to interface the microcontroller to mobile phone and personal computer with the help of graphical user interface (GUI) software. [4]

Iswanto et al worked on Weather Monitoring System with remote radio frequency wireless communication. They used speed sensor opto-coupler for wind sensor, LM35 for temperature sensor, LDR for light intensity, LCD, ATmega16 as microcontroller and RS232 (serial level converter) as well as $\mathrm{Rf}-1020 \mathrm{U}$ as transmitter and receiver. Their aim was to design and construct a system that will measure temperature, wind speed and light intensity but their major challenge is the distance it can cover. [5]

Nandar et al. implemented a microcontroller based wireless weather station, aimed at developing simple, inexpensive and reliable wireless weather station. They used MPX4115A as pressure sensor, DHT11 as temperature and relative humidity sensor and potentiometer as wind direction sensor, LCD, RF module and PIC18F452 as microcontroller [6].

Neha et al developed a wireless weather monitoring system using global system for mobile-communication (GSM). The system was divided into two parts: Transmitter and Receiver's part. The transmitter unit consists of weather sensors, microcontroller, and GSM while the receiver's unit consists of a personal computer (PC) interfaced with GSM through PC serial port. The data from the sensors are collected by the microcontroller and transmit to the receiver's section through wireless medium. These parameters are viewed at the PC using graphical user interface (GUI) programme in the receiver's side [7].

Jemilehin and Obiyemi also worked on weather monitoring by developing a mobile based online weather monitoring system with disaster alert. The system can be used to remotely monitor weather variation for proper management of climate related disaster through the use of early warning system. They harnesses the wide network 
capability of the internet to stream weather information from weather station to a remote online server via a GSM modem, where the information is harvested by the mobile phone applications assigned for it. The setup was divided into three sections: the Node, the Storage/Server, and the mobile application [8].

Setu et al, make use of ZigBee technology to develop weather monitoring system. In their work, they divided the system into two sections; transmitter and receiver section. The transmitter section consists of weather sensors, microcontroller and ZigBee/transmitter while the receiver section consists of ZigBee interfaced with personal computer through PC serial port. The system monitors temperature wind speed, and humidity, the data from the sensors are collected by the microcontroller and transmitted to the receiver section through wireless medium. The transmitted data will be received at the receiver section and displayed on the PC using program in the receiver side [9].

Shailaja and Manchiryal proposed weather monitoring system in Hazardous zones survey. The fundamental point of this proposed framework is to plan a remote climate station which will monitor climate parameters despite the hazardous conditions using ZigBee innovation and send the data to that concern using GSM, SMS strategy [10].

Kirankumar in his work developed a low-cost wireless weather monitoring system using ZigBee wireless module and the parameters measured are temperature, humidity and light intensity. His argument was that the node of wireless sensors network are just two; ZigBee and Bluetooth and on extensive study of the two, ZigBee technology is more reliable for both indoor and outdoor sensors network. He divided the system into two parts: transmitting and receiving part. The major components at the transmitter part are the microcontroller (AT 89C52) ZigBee/Transceiver while the major component at the receiver part are ZigBee/Transceiver, Max 232, and personal computer [11]

Nisha et al also worked on this field using the same technology titled ZigBee based weather monitoring system. The system consists of transmitting as well as receiving section. Transmitting section consists of sensors (temperature, humidity, rain-gauge, wind direction and sun intensity), Micro controller (ARM LPC2148), LCD 16 by 2 and Max 232. The receiver's section consists of ZigBee/Receiver and the personal computers, so the data received can be monitored on PC [12].

Kalyani and Snehlata also used the same technology. They titled their work as a survey on weather monitoring system in agriculture zone using ZigBee. They developed a wireless sensor network based on ZigBee/IEEE802.15.4 standard that can be used to check and monitor the weather parameters through wireless sensors devices during some weather hazard and make the data known to farmers using GSM/SMS techniques. The weather parameters that were measured are temperature, humidity, and wind speed and wind direction [13].
Tanmay et al. developed a weather monitoring system using Wi-Fi. They used readily available sensors for temperature, pressure and humidity measurement whereas wind-speed, wind direction and rainfall were measured using rotary encoder, opto-coupler, tipping bucket technique respectively. The measured data were processed using microcontroller-based system and made available wirelessly on the server for storage and access continuously [14].

\section{Method}

For the design and development of the system, the methodology used involves the software, and hardware implementation. The actual implementation of the system involves the following steps:

(i). System Definition: Broad definition of system hardware including microcontroller, and its interface with display, Anemometer (wind speed sensor), DHT11 (temperature and relative humidity sensor), MPX5100AP (pressure sensor), LDR (Light Dependent Resistor) for light intensity 16x2 LCD (Liquid Cristal Display), MMC Memory/Storage, etc.

(ii). Circuit Design: Selection of ATMEGA328 microcontroller and other interfacing devices as per system definition. Design of hardware circuit and its testing on laboratory kits with some simple microcontroller software routine;

(iii). Generation of schematic diagrams;

(iv). Hardware Modifications: Making any hardware changes found necessary after the initial hardware test, to produce a revised circuit board schematic diagram and layout;

(v). Software Design: Developing algorithm for the system.

(vi). Integration and Final Testing: Integrating the entire hardware and software modules and its final testing for data logging operation.

The complete design is divided into two parts: Hardware Implementation and Software implementation. The system overview includes the power supply, input components, controller, as well as output components.

At modular level of this project implementation the microcontroller processes input data from the various measuring devices, stored it and displayed it on the LCD. External memory was connected to the microcontroller for sufficient storage space, so that the received data can be stored after been processed.

GSM module connected to the microcontroller received command signals for transmitting the weather variables been measured to remote location(s) via the internet. Furthermore, provision was made such that personal computer (PC) can be interfaced with the microcontroller to display the received data. 


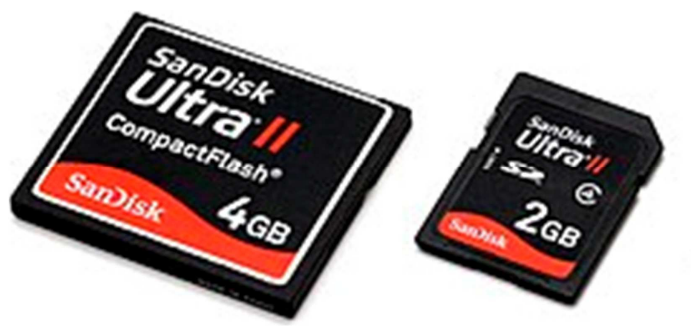

Figure 1. Different capacity of memory card.

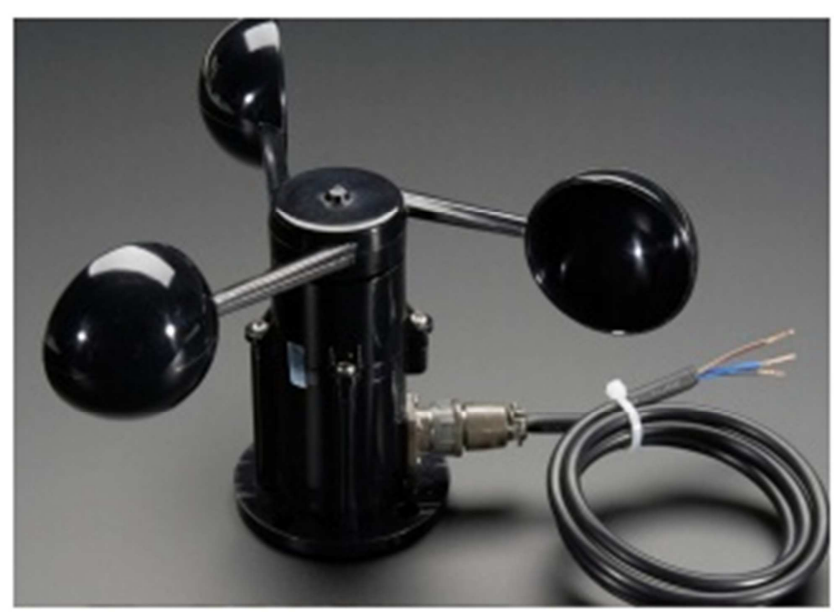

Figure 2. Anemometer (wind speed sensor).

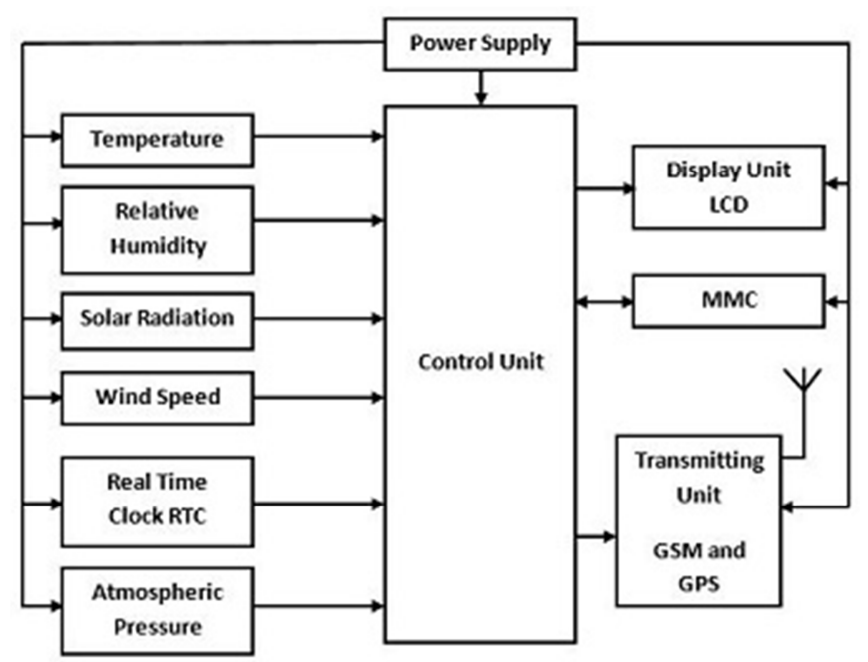

Figure 3. System Block Diagram.

The control unit algorithm is as follows;

(i). Start the microcontroller.

(ii). Configuration and initialization of port i.e. set port direction (input/output pin).

(iii). Display the start-up message on the LCD i.e. name, num. title etc

(iv). Get the sensors value.

(v). Convert sensors value from analog to digital

(vi). Check sampling time for saving

(vii). If yes Display the sensors value on $L C D$, save data on Memory Card, go back to 4, read sensors

(viii).If no display sensors value on LCD, go back to read sensors

(ix). End

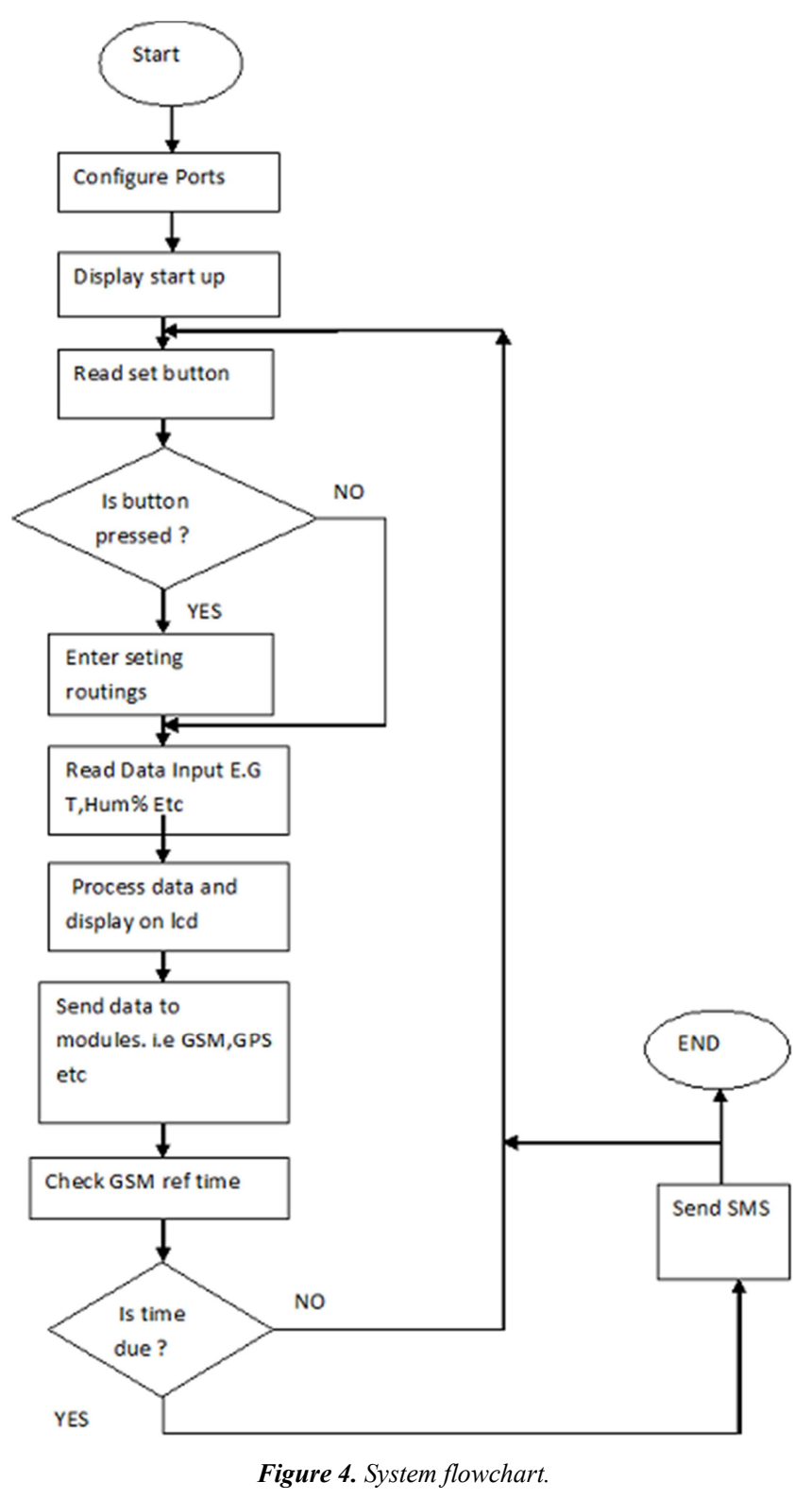

\section{Result and Discussion}

The constructed device was tested by mounting it for a period of one month alongside the standard existing system at two different locations; Abubakar Tafawa Balewa University Bauchi and NIMET at international airport Durum, Bauchi. Sample of the recorded parameters have been summarized as shown in the following tables. For each of the tables, percentage error in measurement were evaluated. As a result of that, the low percentage error obtained served as strong indicator of high accuracy of the newly constructed device. 


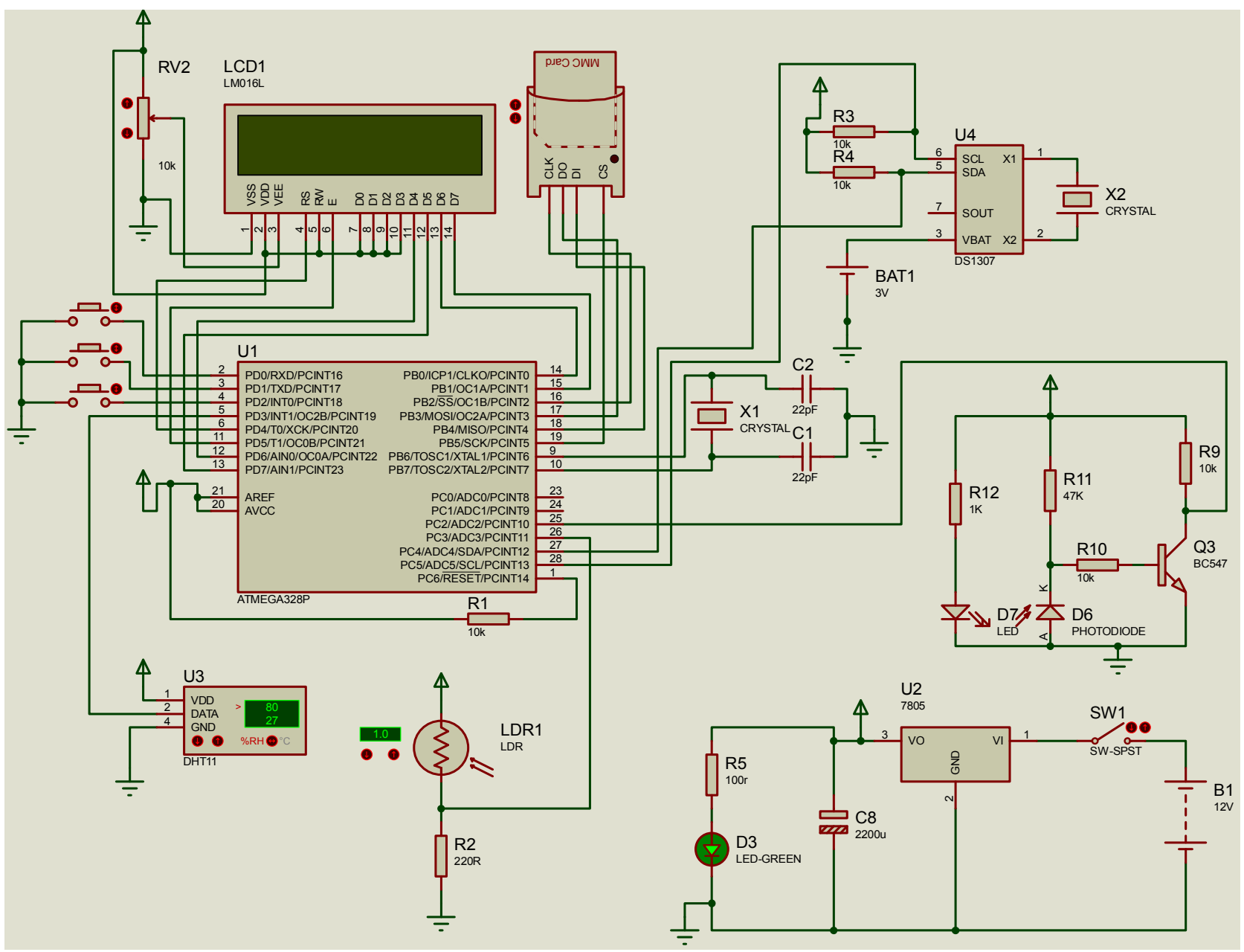

Figure 5. Model Circuit Diagram.

Table 1. Wind speed data recorded on 9/8/2017 at International Airport, Durum, Bauchi.

\begin{tabular}{llll}
\hline Time $(\mathbf{h r s})$ & NIMET value $(\mathbf{m} / \mathbf{s})$ & Constructed device $\mathbf{( m / s )}$ & Difference $(\mathbf{m} / \mathbf{s})$ \\
\hline $7: 00 \mathrm{am}$ & 2.75 & 2.60 & 0.03 \\
$8: 00 \mathrm{am}$ & 1.54 & 1.60 & 0.06 \\
$9: 00 \mathrm{am}$ & 2.06 & 2.10 & 0.04 \\
$10: 00 \mathrm{am}$ & 2.06 & 2.10 & 0.04 \\
$11: 00 \mathrm{am}$ & 3.09 & 3.10 & 0.01 \\
$12: 00 \mathrm{am}$ & 2.06 & 2.10 & 0.04 \\
$1: 00 \mathrm{pm}$ & 0.00 & 0.00 & 0.00 \\
$2: 00 \mathrm{pm}$ & 0.00 & 0.00 & 0.00 \\
$3: 00 \mathrm{pm}$ & 3.60 & 3.65 & 0.05 \\
$4: 00 \mathrm{pm}$ & 1.54 & 1.54 & 0.00 \\
$5: 00 \mathrm{pm}$ & 1.54 & 1.55 & 0.01 \\
$6: 00 \mathrm{pm}$ & 2.06 & 2.10 & 0.04 \\
$7: 00 \mathrm{pm}$ & 1.54 & 1.60 & 0.06 \\
TOTAL & $23.66 \mathrm{~m} / \mathrm{s}$ & $24.04 \mathrm{~m} / \mathrm{s}$ & $0.38 \mathrm{~m} / \mathrm{s}$ \\
\hline
\end{tabular}

Table 2. Wind speed data recorded on 9/8/2017 at International Airport, Durum, Bauchi.

\begin{tabular}{llll}
\hline Time (hr) & Wind speed for NIMET $(\mathbf{m} / \mathbf{s})$ & Wind speed for constructed device $(\mathbf{m} / \mathbf{s})$ & Difference $(\mathbf{m} / \mathbf{s})$ \\
\hline 7:00am & 2.57 & 2.67 & 0.10 \\
8:00am & 4.12 & 4.20 & 0.08 \\
9:00am & 3.60 & 3.70 & 0.10 \\
10:00am & 3.60 & 3.70 & 0.10 \\
$11: 00 \mathrm{am}$ & 2.57 & 2.70 & 0.13 \\
$12: 00 \mathrm{am}$ & 2.06 & 2.16 & 0.10 \\
\hline
\end{tabular}




\begin{tabular}{llll}
\hline Time $(\mathbf{h r})$ & Wind speed for NIMET $(\mathbf{m} / \mathbf{s})$ & Wind speed for constructed device $(\mathbf{m} / \mathbf{s})$ & Difference $(\mathbf{m} / \mathbf{s})$ \\
\hline $1: 00 \mathrm{pm}$ & 2.57 & 2.60 & 0.03 \\
$2: 00 \mathrm{pm}$ & 3.09 & 3.10 & 0.01 \\
$3: 00 \mathrm{pm}$ & 0.00 & 0.00 & 0.00 \\
$4: 00 \mathrm{pm}$ & 2.57 & 2.60 & 0.03 \\
$5: 00 \mathrm{pm}$ & 2.57 & 2.60 & 0.03 \\
$6: 00 \mathrm{pm}$ & 2.06 & 2.20 & 0.14 \\
$7: 00 \mathrm{pm}$ & 1.54 & 1.60 & 0.06 \\
TOTAL & 32.92 & 33.83 & 0.91 \\
\hline
\end{tabular}

Table 3. Wind speed data recorded on 10/8/2017 at International Airport, Durum, Bauchi.

\begin{tabular}{llll}
\hline Time (hr) & Wind speed for NIMET $(\mathbf{m} / \mathbf{s})$ & Wind speed for constructed device $(\mathbf{m} / \mathbf{s})$ & Difference $(\mathbf{m} / \mathbf{s})$ \\
\hline $7: 00 \mathrm{AM}$ & 0.00 & 0.00 & 0.00 \\
$8: 00 \mathrm{am}$ & 1.03 & 1.08 & 0.05 \\
$9: 00 \mathrm{am}$ & 2.57 & 2.60 & 0.03 \\
$10: 00 \mathrm{am}$ & 1.03 & 1.06 & 0.03 \\
$11: 00 \mathrm{am}$ & 1.58 & 0.04 \\
$12: 00 \mathrm{am}$ & 1.54 & 3.12 & 0.03 \\
$1: 00 \mathrm{pm}$ & 3.09 & 2.59 & 0.02 \\
$2: 00 \mathrm{pm}$ & 2.57 & 0.00 & 0.00 \\
$3: 00 \mathrm{pm}$ & 0.00 & 1.56 & 0.02 \\
$4: 00 \mathrm{pm}$ & 1.54 & 1.58 & 0.04 \\
$5: 00 \mathrm{pm}$ & 1.54 & 1.55 & 0.01 \\
$6: 00 \mathrm{pm}$ & 1.54 & 1.08 & 0.05 \\
$7: 00 \mathrm{pm}$ & 1.03 & 1.08 & 0.05 \\
TOTAL & 1.03 & 18.88 & 0.37 \\
\hline
\end{tabular}

Table 4. Recorded temperature from the two sensors (newly constructed device and NIMET) Day 1: 8/8/2017, Day 2 9/8/2018.

\begin{tabular}{|c|c|c|c|c|c|c|c|c|}
\hline \multirow[b]{2}{*}{ Time } & \multicolumn{2}{|c|}{$\begin{array}{l}\text { NIMET Temperature } \\
\text { Readings }\left({ }^{\circ} \mathrm{C}\right)\end{array}$} & \multicolumn{2}{|c|}{$\begin{array}{l}\text { New Device Temperature Readings } \\
\left({ }^{\circ} \mathrm{C}\right)\end{array}$} & \multicolumn{2}{|c|}{ Difference $\left({ }^{\circ} \mathrm{C}\right)$} & \multicolumn{2}{|c|}{ Percentage Error } \\
\hline & Day 1 & Day 2 & Day 1 & Day 2 & Day 1 & Day 2 & Day 1 & Day 2 \\
\hline 7:00am & 21.6 & 22.3 & 22.0 & 23.5 & 0.40 & 1.2 & $1.85 \%$ & $5.38 \%$ \\
\hline 8:00am & 24.5 & 24.1 & 25.0 & 25 & 0.50 & 0.9 & $2.04 \%$ & $3.73 \%$ \\
\hline 9:00am & 25.2 & 25.3 & 26.5 & 26.5 & 1.30 & 1.2 & $5.16 \%$ & $4.74 \%$ \\
\hline 10:00am & 26.4 & 26.5 & 27.5 & 27.5 & 1.10 & 1 & $4.17 \%$ & $3.77 \%$ \\
\hline $11: 00 \mathrm{am}$ & 27.3 & 27.6 & 28.0 & 28.8 & 0.70 & 1.2 & $2.56 \%$ & $4.35 \%$ \\
\hline $12: 00 \mathrm{am}$ & 28.2 & 28.1 & 29.0 & 29.5 & 0.80 & 1.4 & $2.84 \%$ & $4.98 \%$ \\
\hline 1:00pm & 27.7 & 28.8 & 28.0 & 29.9 & 0.30 & 1.1 & $1.08 \%$ & $3.82 \%$ \\
\hline 2:00pm & 26.7 & 29.8 & 27.7 & 29.9 & 1.00 & 0.1 & $3.75 \%$ & $0.34 \%$ \\
\hline 3:00pm & 28.6 & 30 & 29.5 & 31 & 0.90 & 1 & $3.15 \%$ & $3.33 \%$ \\
\hline 4:00pm & 28.4 & 28.5 & 29.5 & 29.5 & 1.10 & 1 & $3.87 \%$ & $3.51 \%$ \\
\hline 5:00pm & 28.5 & 21.5 & 29.5 & 22.5 & 1.00 & 1 & $3.51 \%$ & $4.65 \%$ \\
\hline 6:00pm & 22.8 & 26.2 & 23.5 & 27.0 & 0.70 & 0.8 & $3.07 \%$ & $3.05 \%$ \\
\hline \multirow[t]{2}{*}{ 7:00pm } & 21.9 & 24.5 & 23.0 & 25.0 & 1.10 & 0.5 & $5.02 \%$ & $2.04 \%$ \\
\hline & \multicolumn{6}{|c|}{ Average Percentage Error } & $3.24 \%$ & $3.67 \%$ \\
\hline
\end{tabular}

Table 5. Recorded relative humidity from the two systems (newly constructed device and NIMET) Day 1: 8/8/2017, Day 2: 9/8/2018.

\begin{tabular}{lllllllll}
\hline \multirow{2}{*}{ Time } & \multicolumn{2}{l}{ NIMET Readings \% } & \multicolumn{2}{l}{ New Device Readings \% } & \multicolumn{2}{c}{ Difference \% } & \multicolumn{2}{c}{ Percentage Error } \\
\cline { 2 - 9 } & Day 1 & Day 2 & Day 1 & Day 2 & Day 1 & Day 2 & Day 1 & Day 2 \\
\hline 7:00am & 95 & 94 & 96 & 95 & 1 & 1 & $1.05 \%$ & $1.06 \%$ \\
8:00am & 95 & 88 & 95 & 88 & 0 & 0 & $0.00 \%$ & $0.00 \%$ \\
9:00am & 96 & 87 & 96 & 88 & 0 & 1 & $0.00 \%$ & $1.15 \%$ \\
10:00am & 96 & 83 & 97 & 84 & 1 & 1 & $1.04 \%$ & $1.20 \%$ \\
11:00am & 95 & 77 & 96 & 79 & 1 & 2 & $1.05 \%$ & $2.60 \%$ \\
$12: 00 \mathrm{am}$ & 89 & 71 & 89 & 71 & 0 & 0 & $0.00 \%$ & $0.00 \%$ \\
1:00pm & 94 & 76 & 95 & 76 & 1 & 0 & $1.06 \%$ & $0.00 \%$ \\
$2: 00 \mathrm{pm}$ & 88 & 65 & 89 & 66 & 1 & 1 & $1.14 \%$ & $1.54 \%$ \\
$3: 00 \mathrm{pm}$ & 74 & 65 & 75 & 65 & 1 & 0 & $1.35 \%$ & $0.00 \%$ \\
$4: 00 \mathrm{pm}$ & 73 & 62 & 74 & 62 & 1 & 0 & $1.37 \%$ & $0.00 \%$ \\
$5: 00 \mathrm{pm}$ & 68 & 62 & 69 & 63 & 1 & 1 & $1.47 \%$ & $1.61 \%$ \\
\hline
\end{tabular}




\begin{tabular}{|c|c|c|c|c|c|c|c|c|}
\hline \multirow{2}{*}{ Time } & \multicolumn{2}{|c|}{ NIMET Readings \% } & \multicolumn{2}{|c|}{ New Device Readings \% } & \multicolumn{2}{|c|}{ Difference \% } & \multicolumn{2}{|c|}{ Percentage Error } \\
\hline & Day 1 & Day 2 & Day 1 & Day 2 & Day 1 & Day 2 & Day 1 & Day 2 \\
\hline $6: 00 \mathrm{pm}$ & 68 & 72 & 68 & 75 & 0 & 3 & $0.00 \%$ & $4.17 \%$ \\
\hline \multirow[t]{2}{*}{ 7:00pm } & 70 & 79 & 71 & 79 & 1 & 0 & $1.43 \%$ & $0.00 \%$ \\
\hline & & & \multicolumn{4}{|c|}{ Average Percentage Error } & $0.84 \%$ & $1.03 \%$ \\
\hline
\end{tabular}

\section{Conclusion}

The purpose of this paper was to present produce a simple and cost effective weather station considering the importance of the availability of weather related data the designed system can Measure five weather parameters namely; atmospheric temperature, relative humidity, wind speed, solar radiation and atmospheric pressure. It can also $\log$ in the data for a prescribed period of time. Finally the system has peripheral device that enabled it communicate the data to the end users via the internet. From the results obtained from the tests carried out as shown in tables 1-5 above, it can be concluded that the aim and objectives of the project is achieved.

\section{Future Scope}

This system can be upgraded in the future to have forecasting capabilities by utilizing the previous data collected and stored. Satellite images could also be included to give more accurate weather forecast as the images would include Cloud Motion Vector (CMV), Water Vapor Wind (WVW), Quantitative Precipitation Estimate (QPE), Sea Surface Temperature (SST) etc. The system can be modified to help farmers find out the best time for each crop and specific climatic conditions for proper pest control.

\section{References}

[1] Hatfield, J., G. Takle, R. Grotjahn, P. Holden, R. C. Izaurralde, T. Mader, E. Marshall, and D. Liverman,: Ch. 6: Agriculture. Climate Change Impacts in the United States: The Third National Climate Assessment, J. M. Melillo, Terese (T. C.) Richmond, and G. W. Yohe, Eds., U.S. Global Change Research Program, 150-174 (2014). Available on https://19january2017snapshot.epa.gov/climateimpacts/climate-impacts-agriculture-and-food-supply_html

[2] Walthall, C. L., Hatfield, J., Backlund, P., Lengnick, L., Marshall, E., Walsh, M.,... Ziska, L. H. Climate change and agriculture in the United States: Effects and adaptation (USDA Technical Bulletin 1935). Washington, DC: USDA. (2012).

[3] Edgar M. C. and Juan G. R. R. Portable Weather System for Measuring and Monitoring Temperature, Relative Humidity, and Pressure Based on Bluetooth Communication. American Journal of Networks and communication, University of the Istmo, Ixtepec, Mexico, (2015), 4 (3): 49-53.

[4] Nhivekar G. S. and Mudholker R. R. Data Logger and Remote Monitoring System for Multiple Parameters Measurement Application. e-journal of science and technology, Shivaj University, (2008), India.
[5] Iswanto, and Helman M., Weather Monitoring Station with Remote Radio Frequency Wireless Communication. International Journal of embedded systems and application, Indonesia, (2012), 2 (7): 99-104.

[6] Lay Nandar, Kyaw soe L win, Hla myo Tum Implementation of Microcontroller Based Sensing Unit In Transmitter For Wireless Weather Station. International journal of science, Engineering and Technology Research, (2014), (ISSN: 22787798) 3 (6): 1613-1616.

[7] Neha A. D., Asmita D. R., Smita C., and Nagrale. Wireless Weather Monitoring System Using GSM. International Journal Of Pure and Applied Research in Engineering and Technology, (2014), (ISSN: 2319-507X) 2 (8): 491-504.

[8] Jemilehin A. S. and Obiyemi O. O. Development of Mobile Based Online Weather Monitoring System With Disaster Alert. International Journal of Scientific and Engineering Research, (2013), (ISSN: 2229-5518) 4 (9): 1055-1058.

[9] Setu G., Akash G., Akash P., and Heena S. The Role of ZigBee Technology In Weather Monitoring System. International Journal of Advanced Research in Electrical, Electronic and Instrumentation Engineering, India, (2013), (ISSN: 2320-3765) 3 (5): 1703-1706.

[10] Shailaja N. and Manchiryal K. Weather Monitoring System In Hazardous Zone Survey, International Journal Of Computer Science, Mathematics and Engineering, (2015), (ISSN: on line) 2 (2): 2349-8439.

[11] Kirankumar G. S. Low-cost Wireless Weather Monitoring System. International Journal Of Engineering Technologies and Management Research, (2015), (ISSN: 2454-1907) 1 (1): 35-39.

[12] Nisha G., Varsha G., Sonali K., Archana T. ZigBee Based Weather Monitoring System International journal of Engineering and Science, India, (2015), (ISSN: 2319-1805) 4 (4): 61-66.

[13] Kalyani G. and Snehlata S. D. A Survey on Weather Monitoring System in Agriculture Zone using ZigBee. International Journal of Science and Research, India, (2013), (ISSN: 2319-7064) 4 (1): 192.

[14] Tanmay p., Shobhit G., Akash G., Thakare Y. B. Weather Monitoring System Using Wi-Fi. International journal of Science and Research, (2016),(ISSN: 2319-7064) 5 (11): 891892.

[15] Burroughs, William J., Bob Crowder, Ted Robertson, Eleanor Vallier-Talbot, and Richard Whitaker,: Weather, a Nature Company Guide, Time-Life Books, (1996), Sydney, Australia, $288 \mathrm{pp}$.

[16] Frisinger, H. H. The History of Meteorology: to 1800, Science History Publications, (1977), New York, 148.

[17] Shuman F. G., History of Numerical Weather Prediction at the National Meteorological Centre, Weather and Forecasting, (1989). 4. Pp. 286-296. 